\title{
Heavy Ion Fusion: Prospects and Status*
}

\author{
W. B. Herrmannsfeldt \\ Stanford Linear Accelerator Center \\ Stanford University, Stanford, California 94309
}

\begin{abstract}
The occasion of this Symposium on Fusion Engineering marks almost exactly two decades since the late Al Maschke (BNL) and Ron Martin (ANL) began working on the promising synthesis of high-energy accelerators and inertially confined fusion. Although a start on a large-scale fusion driver is still far in the future, it is possible to mark this occasion by noting progress on several fronts.

Key events in the Heavy Ion Fusion (HIF) field are usually marked by the dates for the International Symposium series which began in 1976 at the Claremont Hotel (Berkeley /Oakland), and most recently in the eleventh meeting in the series at the Princeton Plasma Physics Laboratory in September 1995. The main purpose of this talk will be to review the status of $\mathrm{HIF}$ as it was presented at Princeton, and also to try to deduce something about the prospects for HIF in particular, and fusion in general, from the world and U.S. political scene.

The status of the field is largely, though not entirely, expressed through presentations from the two leading HIF efforts:

1. The U.S. program, centered at LBNL and LLNL, is primarily concerned with applying induction linac technology for HIF drivers. (Details of the LBNL pro-gram will be presented by Roger Bangerter in a paper later in this session.)

2. The European program, centered at GSI, Darmstadt, but including several other laboratories, is primarily directed towards the if linac approach using storage rings for energy compression. However, in contrast to the U.S. program in which target development is in the separate Inertial Confinement Fusion (ICF) program in the DOE, the European program includes target study groups in Spain, Italy, Germany, and Russia. These groups are collaborating with the experimental target groups at the Institute of Laser Engineering, Osaka. Supporting technologies, such as systems studies, reactor chamber studies, etc., are also included in the European HIF program, while in the U.S. these efforts are found both in Inertial Fusion Energy (IFE) and in ICF.
\end{abstract}

Several developments in the field of HIF should be noted:
1. Progress towards construction of the National Ignition Facility (NIF), which was reported to this symposium on Monday, gives strength to the whole rational for developing a driver for Inertial Fusion Energy.

2. The field of accelerator science has matured far beyond the status that it had in 1976. Although the field was bloodied in the politics of the Superconducting Super Collider, technically accelerator projects for basic research, industrial processing, and the production of tritium have all pushed on the frontiers of efficiency, reliability, and high intensity.

3. Heavy Ion Fusion has passed some more reviews, including one by the Fusion Energy Advisory Commit-tee (FEAC), and has received the usual good marks.

4. Sadly, HIF has lost one of its founding fathers; $\mathrm{Al}$ Maschke passed away in the Spring of 1995. The HIF Symposium in September was dedicated to Al's memory. Ron Martin gave a fascinating talk relating the history of HIF to his own and Al Mascke's parallel efforts.

5. As the budgets for Magnetic Fusion have fallen, the pressures on the Office of Fusion Energy (OFE) have intensified, and a move is underway to shift the HIF program out of the IFE program and back into the ICF program in the Defense Programs (DP) side of the DOE. The outcome of this strategy is not known at the time when these lines are being written. In any case, it is important to note that inter-national collaborations in IFE/HIF would still be with the civilian energy program in OFE, not with the ICF/DP program. We hope the above acronym-loaded paragraph is understandable to our foreign colleagues for whom this is an important political issue.

\section{INTRODUCTION}

The Heavy Ion Fusion (HIF) program is the only program addressing inertial confinement fusion in the Office of Energy Research (OER) of the DOE. The purpose of the HIF program is to evaluate the technology of heavy-ion accelerators for prospects as drivers for commercial power production from ICF. Early in the study of HIF, two types of accelerators were identified as suitable driver candidates:

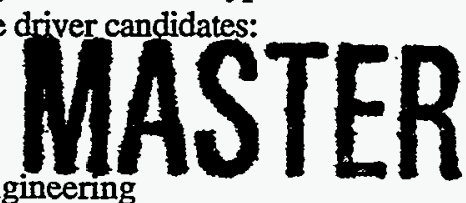

*Work supported by Department of Energy contract DE-AC03-76SF00515.

Invited talk presented at the 16th IEEE/NPSS Symposium on Fusion Engineering

Champaign, Illinois, October 1-5, 1995. 
1. An if linear accelerator that would sequentially fill a series of storage rings that would stack and multiply the current by the number of final stacking storage rings.

2. A single-pass linear induction accelerator using accelerating wave forms to compress and confine the bunch during acceleration. Multiple parallel beams are accelerated through the induction cores, thus enabling this approach to deliver enough energy to the target.

In order for the U.S. HIF program to make any progress, it was necessary to select one of the above options and concentrate resources. Since approximately 1984, the U.S. program has accordingly concentrated on the induction accelerator approach for two reasons:

1. Induction linac technology was better known in the U.S, where it had been used for fusion and directed energy projects. Thus it was possible to follow both approaches in a complementary arrangement with the European program which concentrated on the if accelerator method.

2. The cost of the development path appears much less for the induction accelerator because all the key issues are in the front end of the accelerator. By contrast, the if accelerator method has its key issues in the storage rings. The requirement for a high-current if linac to fill the storage rings is an expensive item needed to "buy into" this approach. The fact that the GSI in Darmstadt has a large heavy-ion if linac makes this approach more desirable for them than it could be in the U.S.

The above introductory comments have been repeated many times in the last $10-15$ years. They are however necessary to put into context the treatment that follows in which we report on programs from the U.S. and from the rest of the world where entirely different technologies are being used.

\section{THE INTERNATIONAL HIF COMMUNITY}

Inertial Confinement Fusion has been so much a part of the U.S. Defense Programs scene in the DOE that it is frequently difficult to even convince people that there is international interest in the subject. It is then even harder to tell U.S. scientists that the programs in other countries are very good and are worthy of their attention. Classification works both ways; when we cannot tell what we are doing, we do not learn what others are doing. For too many years the very word holraum was forbidden; thus, the U.S. scientist at a meeting could not ask a Polish scientist about his development of holraum targets, even though very nice targets were displayed at meetings several years ago.

Now that most, but not all, classification barriers have been lowered, international interest is on the rise. In almost all cases, the reason for this interest is for fusion energy. Although U.S. ICF scientists universally proclaim that energy production is their ultimate objective, there are political reasons to downplay the ciyilian applications. While Magnetic Fision

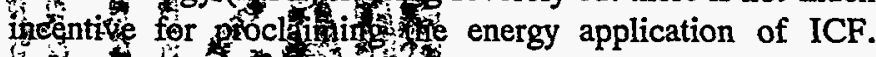

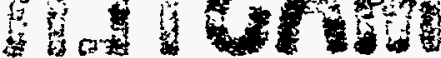

As in other areas in accelerator science, such as very high-current pulsed machines or high-current proton linacs, it is the defense application that provides the funds even though many fine civilian applications can be defined. It is a failing of the U.S. DOE that many promising accelerator applications are abandoned for lack of support. Often-as in this case and for others such as heavy ion medical therapy facilities, commercial synchrotron light sources, and some FEL applications-the good U.S. ideas are recognized and frequently commercialized in other countries. The Office of Energy Research is just now conducting a series of hearings for an Accelerator Technology Assessment Panel to determine what the promise of the field is and how to address the opportunities.

The recent symposium was held at a magnetic fusion facility, the Princeton Plasma Physics Laboratory. The director of PPPL, Ron Davidson, provided the full hospitality of the laboratory. This was the second time in two meetings that the symposium was held at a magnetic fusion laboratory; the previous symposium was at ENEA, Frascati. That meeting, organized by R. A. Ricci and S. Atzeni, went so well that it seem worth trying the same idea in the U.S. A highlight of the week was the very upbeat presentation of the status of magnetic fusion and particularly of the tritium experiments on TFTR. This presentation by Dale Meade included a well organized tour of the TFTR. The good physics results of running tritium in TFTR are in sharp contrast to the frighten-ing budget situation. (How can we complain about missed opportunities for accelerators when we see the threatened shutdown of the TFTR under our very noses?)

The statistics of the international involvement were that of 120 registered attendees, 44 (37\%) were from nine foreign countries, with the largest and second largest foreign contingents from Germany and Russia, respectively. Germany continues to have the strongest European program; if it is compared just to the U.S. HIF program, it is the largest in the world. However, this is probably not a fair comparison because it ignores many scientists in the U.S. ICF program whose direct counterparts are in the German HIF program. Nevertheless, the German program is very strong, and it will host the next HIF Symposium in 1997.

The conference Keynote Address was presented by Horst Klein, Frankfurt. His talk stressed the many common characteristics of the technology needed for numerous applications of high-power particle accelerators. Proton accelerators for neutron spallation provide neutrons for physics research as well as for tritium breeding, nuclear waste transmutation, and for the energy amplifier which uses the neutrons to make a controlled reactor out of a subcritical assembly of fissionable material. Even thorium which is widely available could be used as a fuel, as could plutonium which is excess from reactors and nuclear weapons. Other applications of high-intensity accelerators, besides HIF of course, include materials processing and toxic waste clean up. Klein noted interest in a new International Fusion Materials Irradiation Facility (IFMIF) needed to provide data for the next magnetic fusion reactor demonstrations such as for the International Thermonuclear 


\section{DISCLAIMER}

Portions of this document may be illegible electronic image products. Images are produced from the best available original document. 
Experimental Reactor (ITER). Accelerators for all these applications have in common the needs for economy, emittance control, care in minimizing beam loss, and especially care in accelerating space charge dominated beams at low kinetic energy.

\section{SUMMARIES OF NATIONAL PROGRAMS}

In the following brief paragraphs, we will attempt to touch on the key elements of each of the major program elements. We define these as the U.S. (where LBNL and LLNL cover distinctly different aspects), Germany (where both the GSI-led program and a new EC effort is beginning), Italy, Russia, Spain, and Japan. This survey will be far from complete because it would be too incoherent to mention every paper, especially those from the U.S. and Germany, in this way.

1. The LBNL program led by Roger Bangerter has the main responsibility for the U.S. effort to determine if an Induction Linac can be used as an HIF driver. The LBNL program will be described later in this session. The Induction Linac Systems Experiment (ILSE) has been pro-posed and repeatedly favorably reviewed. ILSE would demonstrate all the key elements of an HIF driver at full scale in aperture, voltage gradients, and line charge density. In other parameters, notably pulse length and total kinetic energy, ILSE represents a scaled experiment in order to make a test that is far less expensive than a full scale driver. ILSE would use potassium ions rather than the usual cesium or heavier ions in order to more reasonably test all aspects of the driver including magnetic focused high-current beams. The ELISE portion of ILSE has been approved for construction. It features all the front part of ILSE; i.e., that part using electrostatic focusing, which is the first $5 \mathrm{MeV}$. The $2 \mathrm{MeV}$ electrostatic quadrupole focused injector has been completed and is successfully operating. This injector is being used for innovative studies of neutralized final focusing experiments. The conference heard engineering descriptions and more detailed poster papers on all the engineering problems in ELISE. ILSE will be located in the nowempty experimental hall of the old LBNL Bevatron.

2. Lawrence Livermore National Laboratory (LLNL) is the leading center for ICF in the world. Several papers, led by presentations by John Lindl on the physics of indirect drive, and by Mike Campbell on the National Ignition Facility (NIF), affirmed that leading position. This Fusion Engineering Symposium will have already heard these same speakers give what will most probably be very similar talks.

The LLNL HIF program led by Alex Friedman is providing engineering and computational support for LBNL in various ways. The primary local HIF accelerator effort at LLNL is to study ideas of recirculating the beams in an induction accelerator. The primary reason why recirculation is interesting is that it would permit reusing the large accelerating modules. The major concerns are over maintain- ing overall energy conversion efficiency (it is well known that an overall efficiency of around $20 \%$ or more is needed for economical energy production), maintaining adequate longitudinal and transverse beam control, limiting emittance growth due to the bending system, and maintaining vacuum quality adequate to permit multiple passes through the same structure. The LLNL group is building a small ring structure featuring permanent magnet quadrupoles and electrostatic bending elements.

An important part of the LLNL effort is power-plant dosign work led by Ralph Moir. He reviewed the studies of Liquid Wall IFE Power Plants. The liquid protection affords several advantages including especially that exist-ing steel can be used, thus avoiding the need for a materials testing facility. Several different liquid-wall designs have appeared over the past years; it seems that a count of power-plant designs would show at least as many ICF do signs as for MFE. Moir's HYLIFE-II design uses moving jets of Flibe $\left(\mathrm{Li}_{2} \mathrm{BeF}_{4}\right)$ to completely sweep out the chamber between shots, and then to provide full coverage for all the exposed metal in the chamber.

3. The German program is led by GSI, Darmstadt; the principal spokesman is Ingo Hofmann. This program features work on the if linac/storage ring approach plus experimental work on beam focusing and ion/plasma inter-actions. The longitudinal stability of high-current beams in storage rings is being addressed at the Experimental Storage Ring (ESR) at GSI. The experiments show that circulating beams can exist with currents well above the Keil-Schnell criterion.

4. The European Study Group has been formed under Gunther Plass, CERN. Their objective is to perform a design study for an ICF ignition facility which would be a heavy ion counterpart to the U.S. National Ignition Facility (NIF). A preliminary design for one module of the HIF Ignition Driver is shown in Fig. 1. The basis of this study would be the if linac/storage ring approach. We would expect to learn a great deal more about this program, should it receive support, at or before the next HIF symposium.

5. Target designs for the European Study Group were doscribed by S. Atzeni, ENEA, Frascati, Italy. He reported on work by several groups in Spain, Germany, and Italy. Their goal is a reliable design for ignition at $2 \mathrm{MJ}$ and high gain at $5 \mathrm{MJ}$. This reviewer gains the perspective that while the elaborate experimental basis of U.S. studies far exceeds anything available to the rest of the world, in the special area of ion beam targets, the U.S. may no longer be leading the field.

6. The important topics of beam/plasma interaction physics is the subject of work at a number of centers. Chamber transport was reported by $D$. Callahan, LLNL, and by several other authors on special topics such as plasma lenses by Tauschwitz et al., LBNL, and on self-pinched transport and neutralized transport by C. Olson, D. Hanson, and 
J. Poukey, Sandia National Laboratory. Beam-plasma interaction physics and deposition studies were also reported by several authors including Z. Zinamon, Israel, B. Sharkov, ITEP, Chabot et al., France, and by the GSI group able to make increasingly relevant experiments using beams from the ESR.

7. The HIF Research in Spain was presented by J.M. Perlado. This work is the product of two groups at the Universidad Politécnica de Madrid. Perlado covered an illumination scheme that combines elements of direct and indirect drive. He also reported on work on target design computer programs including adaptive mesh schemes and a detailed opacity model. The Spanish group was able to compare theoretical models with experiments from the French laser program at Limeil.

8. There were several speakers from Russia reporting on a variety of programs. M. M. Basko reported on conceptual design work at the Institute for Theoretical and Expermental Physics (ITEP), Moscow. They found conservative target designs needing $10 \mathrm{MJ}$ in a holraum target. Dmitri Koshkarev, ITEP, displayed a poster with an innovative design for a linac that accelerates both positive and negative singly-charged ions of four isotopes of platinum. Parallel RFQ's are used until $100 \mathrm{MeV}$ at which point the beams are combined using their mass and charge differences to preserve emittance.

9. Japan has the largest ICF program for energy and physics (non-military) applications. The work of the Institute for Laser Engineering, Osaka, was described by K. Nishihara. Another innovative accelerator concept was described in a poster by $T$. Hattori, Tokyo Institute of Technology, in which cost and size of the accelerator are controlled by using a high gradient in a structure with high shunt impedance. They calculate conditions based on $80 \%$ beam loading; wall losses would be prohibitive at a lower level of beam loading.

\section{SUMMARY}

We have attempted to review the recent HIF Symposium by touching on the efforts of various national programs in order to illustrate the international aspects of HIF. With more time and space, we could have gone on to emphasize the innovative experiments and designs that were reported in Princeton. We have chosen the papers we did discuss based on how they represent their national efforts and on how innovative they appeared to this reviewer. We have also chosen experiment over theory whenever possible. The choice of paper and how it was treated was in every case a purely personal and arbitrary expression of this reviewer's opinion. I was impressed with the high quality of the presentations and of the amount of innovation displayed in spite of the passage of time and the low budget available for this work.

\section{A FINAL PERSONAL NOTE}

I have always thought that it would be impossible to make an ion source for multiple-charged ions that would retain adequate brightness for HIF. I felt that the high space charge simply rules out such a source. In spite of my knowledge on this point, Shmuel Eylon and Enrique Henestroza have built such a source and have calculated the emittance of the separated beams. A schematic of the multiple-charge ion source is sown in Fig. 2. This was presented as a poster paper by someone other than the authors, neither of whom has able to attend the symposium due to budget constraints. In fact, neither of these authors have a permanent position in the HIF program because of budget limits. Their paper shows that what I think to be true does not always agree with the facts.

\section{RE FERENCE}

Proceedings of the HIF Symposium will be published in the joumal FUSION ENGINEERING AND DESIGN by Elsevier Science Publishers B.V., Amsterdam

\section{DISCLAIMER}

This report was prepared as an account of work sponsored by an agency of the United States Government. Neither the United States Government nor any agency thereof, nor any of their employees, makes any warranty, express or implied, or assumes any legal liability or responsibility for the accuracy, completeness, or usefulness of any information, apparatus, product, or process disclosed, or represents that its use would not infringe privately owned rights. Reference herein to any specific commercial product, process, or service by trade name, trademark, manufacturer, or otherwise does not necessarily constitute or imply its endorsement, recommendation, or favoring by the United States Government or any agency thereof. The views and opinions of authors expressed herein do not necessarily state or reflect those of the United States Government or any agency thereof. 


\section{Preliminary Design for Ignition Driver}

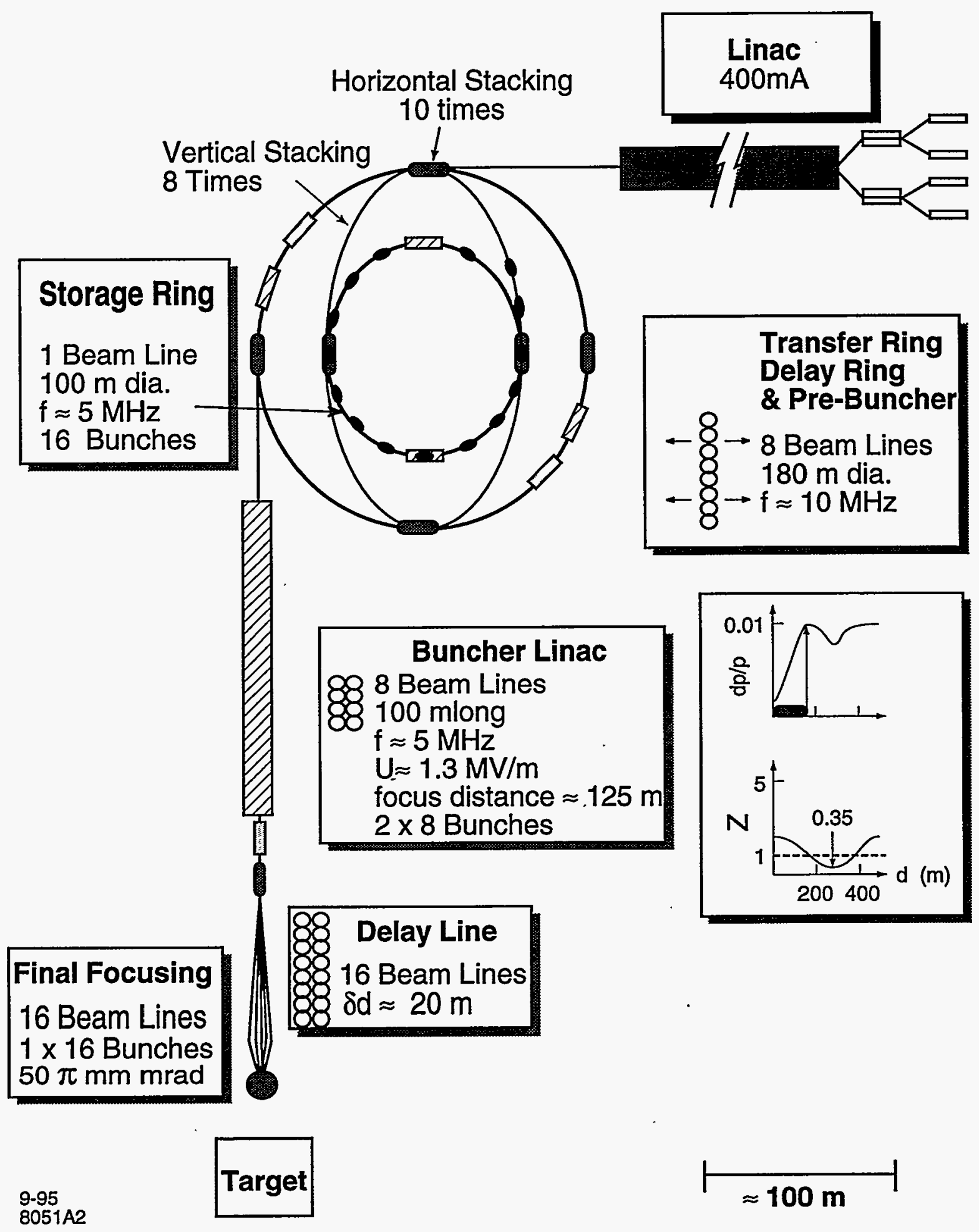

Figure 1. A preliminary design for one module of the HIF Ignition Driver. Figure provided by M. Stetter and I. Hofmann, GSI, private communication. 


\section{High Charge State Beam Source Schematics}

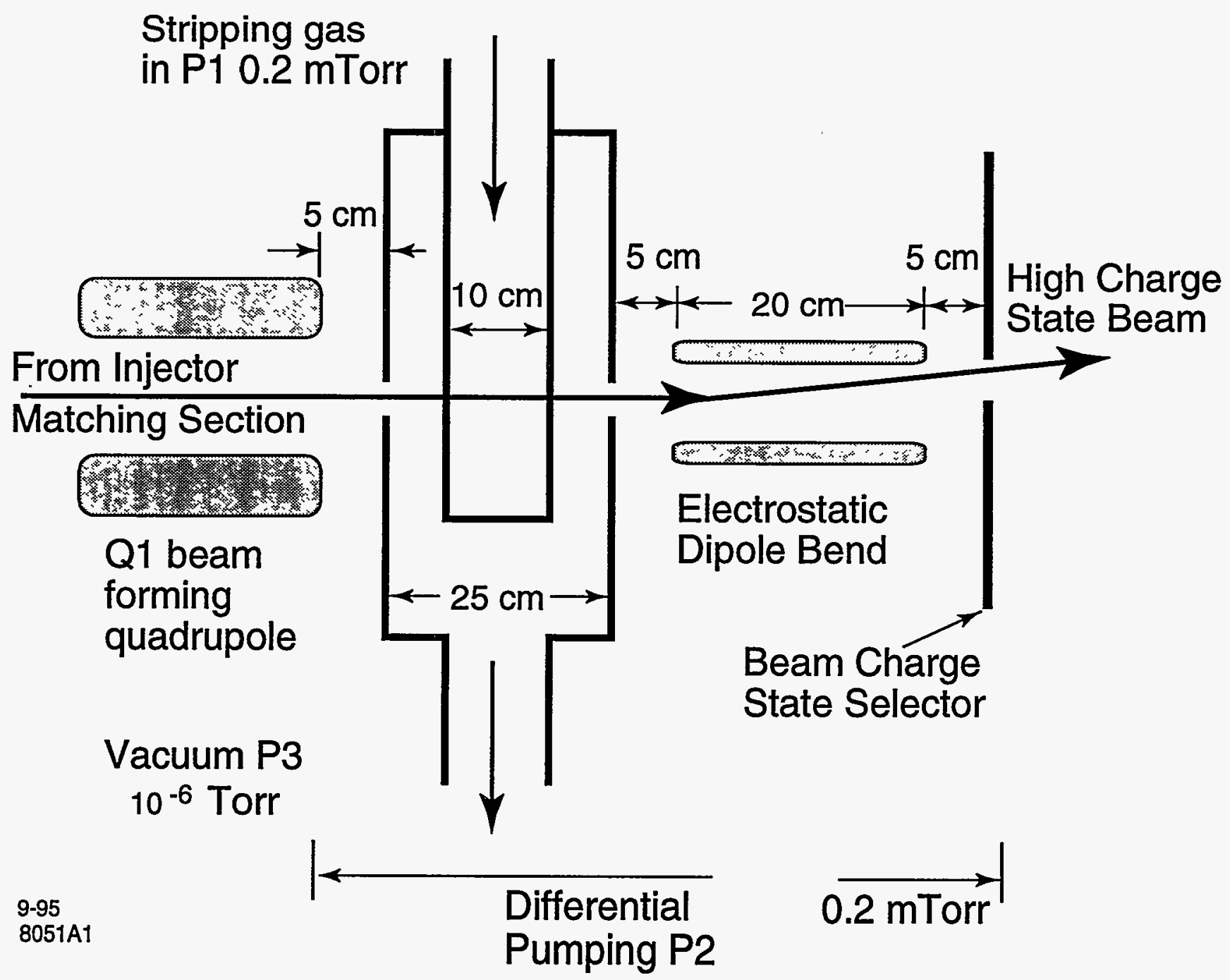

Figure 2. A schematic of the multiple-charge ion source. 